\title{
Stochastic Modelling of Annual Rainfall at New-Bussa
}

\author{
Lawal Adamu ${ }^{1}$, Hakimi Danladi ${ }^{2}$., Laminu Idris ${ }^{3}$ \\ 1.Centre for preliminary and Extra-mural Studies, Federal University of Technology Minna, Nigeria. \\ 2. Department of Mathematics and Statistics, Federal University of Technology Minna, Nigeria \\ 3. Department of Mathematics and Statistics, Federal University of Technology Minna, Nigeria
}

\begin{abstract}
This paper deals with the variations of annual rainfall in New-Bussa based on Markov Chain models. This principle was used to formulate a three state model for annual rainfall distribution in NewBussa.The model is designed such that if given any of the three state in a given year, it is possible to determine quantitatively the probability of making transition to any other two states in the following year(s) and in the long-run. The result from the model shows that in the long-run 70\% of the annual rainfall in New-Bussa will be State1, 27\% will be state 2 and 3\% of the annual rainfall will be State 3. The model could therefore be used to make a forecast of the annual rainfall pattern. This could provide some information for the Crop and Fish farmers, artisanal Fishermen, the Hydroelectric power generating station and the government that could be used to plan strategies to boost their production in New -Bussa and the environment.
\end{abstract}

Keywords: Markov Model, Transition probability, annual rainfall, crop and fish farmers

\section{Introduction}

Rainfall modelling and prediction is increasingly in demand because of the uncertainty that is involved with rainfall and the dependence of Agriculture production and management of water resource on rainfall variability and quantity. The generation of rainfall and other climate data needs a range of models depending on the time and spatial scales involved. Cox and Isham (1994) reported in[4] presented three broad types of rainfall models, namely, empirical statistical models, models of dynamic meteorology and intermediate stochastic models. The idea behind this classification is the amount of physical realism incorporated into the model structure. In the empirical statistical models, empirical stochastic models are fitted to the available data. The models for the generation of annual, monthly and daily rainfall and climate data are of this type. In the models of dynamic meteorology, large systems of simultaneous nonlinear partial differential equations, representing fairly realistically the physical processes involved, are solved numerically. These are generally used for weather forecasting and not for data generation. In intermediate stochastic models, a modest number of parameters are used to represent the rainfallprocess, the parameters being intended to relate to underlying physical phenomena such as rain cells, rain bands and cell clusters. These types of models are used for the analysis of data collected at short time interval such as hourly. Gabriel and Neumann [5] studied the sequence of daily rainfall occurrence. They found that the daily rainfall occurrence for Tel Aviv data was successfully fitted withthe first-order Markov chain model. Meanwhile, Kottegoda et al.[7] reported that a first order Markov chain model wasfound to fit the observed data in Italy successfully. Themodel was based on the assumption that there is a dependency of the daily rainfall occurrence to that of theprevious day. Allen and Haan [1] used a multi-state (7 x 7) Markov chain model and employed a uniform distribution for each of the wet states except for the last, for which an exponential distribution was used. Due to the lack of sufficient number of data items in the last class for each month, the values in this class were lumped together and only one value of the exponential parameter was estimated to generate the rainfall depth in the last class for all the months. Tamil and Samuel[9] used Markov chain to model annual rainfall in Tamil Nadu, India, 100 years(1901-2000) annual rainfall data was used. Class interval was formed for the data and each treated like a state, seven states were obtained and (7x7) matrix formed the transition probability matrix. The uniform random states were also formed by generating uniform random number. Which was used to generate synthetic time series for states. When the synthetic time series was compared with the actual rainfall data it was discovered that, the year 2001 and 2002 actual rainfall values do not match with the synthetic rainfall values for these years. They concluded that the long range forecastingbased on the model does not give more accuracy but could be used only to forecast the futuretrend, the same Markov chain can be furtherdeveloped to forecast with high accuracy. Markov modelling is one of thetools that can be utilized to assist planners in assessing the rainfall .Akintunde et al [2] modified the Chapman- Kolmogorov Equation (CKE) and applied it to model thedaily precipitation data of Abeokuta, Ogun State, Nigeria.This gave the best fit for precipitation pattern which isrelevant in the development of new growth and yieldmodels of major crops such as maize, sorghum and soyabean; enabling farmers to estimate the distribution of cropyield as the growing season progressed. Jimoh and Webster[3] determined the optimum order of a Markov chain modelfor daily rainfall occurrences at 5 locations in Nigeria usingAIC and BIC. It was concluded that caution is needed withthe use of AIC and BIC for determining the optimum orderof the Markov model and the use of 
frequency durationcurves can provide a robust alternative method of modelidentification. Jimoh and Webster [6] also investigated theintra-annual variation of Markov chain parameters for 7 sites in Nigeria. They found that there was a systematicvariation in the probability of a wet day following a dry dayas one moves northwards and limited regional variation. Ageneral conclusion is that a first order Markov model isadequate for many locations but second or higher ordermodel may be required at other locations or during sometimes of the year. Abubakar et al [10] formulate a four state Markov model of annual rainfall in Minna with respect to crop production in the region. They discovered that most of the annual rainfall in Minna in the long-run will be Moderate rainfall .This paper therefore, considers a three state model in discrete time to predict annual rainfallpattern inNew Bussa. New Bussa is located at $9^{\circ} 53^{\prime} \mathrm{N}, 4^{\circ} 31^{\prime} \mathrm{E}$ (altitude $561 \mathrm{ft}$ or 170 meters), Borgu local government area of Niger state, Nigeria. One of the Hydroelectric Power generating stations of the country is located in this area. Most of people that live in this area are Fish farmers, artisanal fishermen and crop farmers because of the Hydroelectric Power generating Dam and the surrounding rivers. The data used in the research work was collected from archive of National Institute for Freshwater Fisheries Research (NIFFR), New-Bussa.

\section{Formulation of The Model}

Suppose that the amount of annual rainfall in New Bussa in a year is considered as a random variable $X$ the collection of this random variable over the years (n) constitutes a stochastic process $X_{n} \quad, \quad n=0,1,2,3 \ldots \ldots \ldots \ldots \ldots . .$. Abubakar et al[11]

It is assumed that this stochastic process satisfies Markov property of first order dependence.

A first order Markov chain could be defined as asequence $\mathrm{X} 0, \mathrm{X} 1, \ldots$ of random variables with the property that the conditional probability distribution of $\mathrm{Xn}+1$ given $\mathrm{X}_{0}, \mathrm{X}_{1}, \ldots \mathrm{Xn}$ depends only on the value of $\mathrm{Xn}$ but not further on $\mathrm{X}_{0}, \mathrm{X}_{1}, \ldots \mathrm{Xn}-1$. That is, for any set of values $\mathrm{h}, \mathrm{i} . . \mathrm{j}$ indiscrete state space

$\mathrm{P}\left(\mathrm{x}_{\mathrm{n}+1}=\mathrm{j} \mid \mathrm{x}_{0}=\mathrm{h} \ldots \mathrm{Xn}=\mathrm{i}\right)=\mathrm{P}\left(\mathrm{x}_{\mathrm{n}+1}=\mathrm{j} \mid \mathrm{x} n=\mathrm{i}\right)=\mathrm{P}_{\mathrm{ij}} \mathrm{i}, \mathrm{j}=1,2,3 \ldots$ Howard $(8)$.

Let the annual rainfall be modelled by three State, Markovmodel.

State1: Annual rainfall within the of range 64omm - 1102.3mm

State2: Annual rainfall within the of range $1102.3 \mathrm{~mm}-1564.6 \mathrm{~mm}$

State3: Annual rainfall within the of range1564.6mm - 2026.9mm

The transition between the states is described by thetransition diagram in figure 1 and probability Matrix P.

$P=\left[\begin{array}{ccc}p_{11} & p_{12} & p_{13} \\ p_{21} & p_{22} & 0 \\ p_{31} & 0 & 0\end{array}\right]$

The matrix $\mathrm{P}$ is homogeneous transition stochastic matrix because all the transition probabilities $\mathrm{P}_{\mathrm{ij}}$ are fixed and independent of time. The transition probabilities must satisfy

$p_{i j \geq 0}, i j=1,2,3 \quad$ and $\quad \sum_{j=1}^{3} p_{i j}, \quad i=1,2,3$

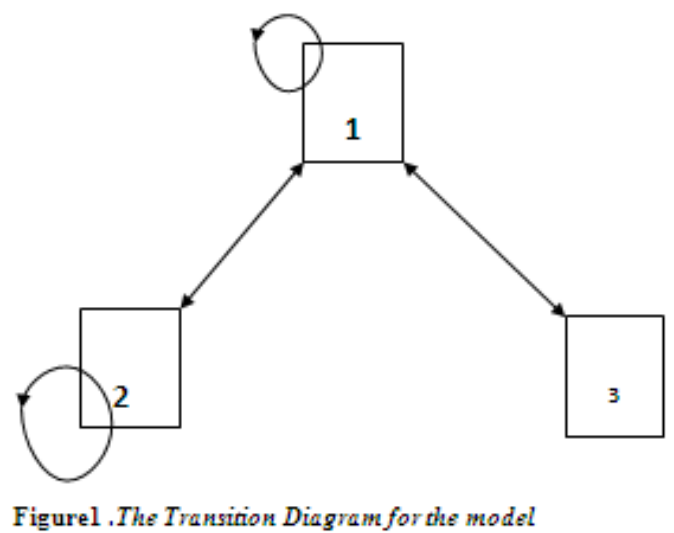

Following Cox and Miller[12] and Abubakar et al [10] 
Let $P^{(n)} \quad$ for $\quad n=0,1,2, \ldots \ldots \ldots \ldots \ldots . .$. be our probability state vectors of the Markov chain, where $P_{i}^{(n)}$ is the probability that the annual rainfall is in the $i^{t h}$ state at the $n^{\text {th }}$ observation. In particular, $P^{(0)}$ is the initial state vector of the Markov chain and $P^{(n)}$ is the state vector at the $n^{\text {th }}$ observation

Then we can write $p^{(n+1)}=P^{(n)} P$

Where $\mathrm{P}$ is our transition matrix and $p^{(n+1)}$ is the state vector at the $(n+1)^{\text {th }}$ observation. on iteration, we have

$$
p^{(n)}=p^{(0)} P^{n}
$$

Thus the initial state vector $P^{(0)}$ and the transition matrix $\mathrm{P}$ determine the state vector $P^{(n)}$ at the $n^{\text {th }}$ year.

If we now, let $P^{(n)}=\left[\begin{array}{lll}p_{1}^{n} & p_{2}^{n} & p_{3}^{n}\end{array}\right]$

denote the probabilities of finding the annual rainfall in any of the three states at the $n^{\text {th }}$ year and also let $P^{(0)}=\left[\begin{array}{lll}p_{1}^{0} & p_{2}^{0} & p_{3}^{0}\end{array}\right]$

denotes the initial state vector, then the three state First order Markov Chain model for prediction of annual rainfall in New-Bussa can be written as:

$$
\left[\begin{array}{lll}
p_{1}^{n} & p_{2}^{n} & p_{3}^{n}
\end{array}\right]=\left[\begin{array}{lll}
p_{1}^{0} & p_{2}^{0} & p_{3}^{0}
\end{array}\left[\begin{array}{ccc}
p_{11} & p_{12} & p_{13} \\
p_{21} & p_{22} & 0 \\
p_{31} & 0 & 0
\end{array}\right]^{n}\right.
$$

\section{Limiting State Probabilities}

The state occupation probabilities is independent of the starting state of the process, if number of the time the state transition is large thus the process reaches a steady state after a sufficiently large period of time. This is equilibrium distribution

$$
\pi=\left(\begin{array}{llll}
\pi_{1} & \pi_{2} & \pi_{3}
\end{array}\right) \text { Howard[8] }
$$

If we let $n \rightarrow \infty$ in equation (2) we have $\pi=\pi p$

and also $\pi=\sum_{i=1}^{3} \pi_{i}=1$ Abubakar et al [10]

these equations will be use to find the limiting state probabilities for our model

\section{Application}

Table1:A summary of annual rainfall in New-Bussa between 1980-2013 and states distribution(source:[13])

\begin{tabular}{|l|l|l|}
\hline Annual rainfall in $\mathrm{mm}$ & Frequency & State \\
\hline $640-1102.3$ & 24 & 1 \\
\hline $1102.3-1564.6$ & 9 & 2 \\
\hline $1564.6-2026.9$ & 1 & 3 \\
\hline
\end{tabular}

The transition count matrix is shown below

$$
M=\left[\begin{array}{ccc}
18 & 4 & 1 \\
4 & 5 & 0 \\
1 & 0 & 0
\end{array}\right]
$$

From equation (5), using the maximum likelihood estimator i.e

$$
p_{i j}=\frac{f_{i j}}{\sum_{j=1}^{3} f_{i j}}
$$

$$
i j=1,2,3 \text { Tamil and Samuel [9] }
$$


Where $f_{i j}$ is the historical frequency of transition from state $i$ to state $j$, we to obtained the probability matrix given below

$$
\begin{aligned}
P=\left[\begin{array}{ccc}
\frac{18}{23} & \frac{4}{23} & \frac{1}{23} \\
\frac{4}{9} & \frac{5}{9} & 0 \\
1 & 0 & 0
\end{array}\right] P=\left[\begin{array}{ccc}
0.783 & 0.174 & 0.043 \\
0.444 & 0.556 & 0 \\
1 & 0 & 0
\end{array}\right]
\end{aligned}
$$

n-Step Transition Probability

From equation (1), we have on iteration

$$
\begin{aligned}
& P^{2}=\left[\begin{array}{lll}
0.733 & 0.233 & 0.034 \\
0.595 & 0.386 & 0.019 \\
0.783 & 0.174 & 0.043
\end{array}\right] \\
& P^{6}=\left[\begin{array}{lll}
0.698 & 0.272 & 0.030 \\
0.694 & 0.276 & 0.030 \\
0.699 & 0.271 & 0.030
\end{array}\right] \\
& P^{10}=\left[\begin{array}{lll}
0.697 & 0.273 & 0.030 \\
0.697 & 0.273 & 0.030 \\
0.697 & 0.273 & 0.030
\end{array}\right] \\
& P^{10}=\left[\begin{array}{lll}
0.70 & 0.27 & 0.03 \\
0.70 & 0.27 & 0.03 \\
0.70 & 0.27 & 0.03
\end{array}\right] \text { corrected to } 2 \text { decimal places }
\end{aligned}
$$

\section{Limiting State Probabilities}

As $n$ increases $P^{n}$ gets closer and closer to (6) that is, $n \geq 10$ the transition probabilities stabilises to (6) and from equation (2) with the initial state probability vector $\left(\begin{array}{lll}1 & 0 & 0\end{array}\right)$ we have

$$
\begin{aligned}
& p^{0} p^{n}=\left(\begin{array}{lll}
1 & 0 & 0
\end{array}\right)\left[\begin{array}{lll}
0.697 & 0.273 & 0.030 \\
0.697 & 0.273 & 0.030 \\
0.697 & 0.273 & 0.030
\end{array}\right]=\left(\begin{array}{lll}
0.697 & 0.273 & 0.030
\end{array}\right) \\
& =\left(\begin{array}{llll}
0.70 & 0.27 & 0.03
\end{array}\right) \text { corrected to } 2 \text { decimal places }
\end{aligned}
$$

From equation (4) and (6) the limiting state vector is given by

$$
\pi=\pi P=\left(\begin{array}{lll}
0.70 & 0.27 & 0.03
\end{array}\right)
$$

\section{Discussion of Result}

The result shows that the probabilities to have a rainfall in state 1 , state 2 , and state 3 , in the first year, giventhat it is in state 1 at present are $0.783,0.174$ and 0.043 respectively. The probabilities of state 1 and state 2 dropped slowly to 0.70 and 0.03 in about ten years. However, the probability of state 2 increased to the 
maximum of 0.27 within the same period of time. This shows that in the long-run $70 \%$ of the annual rainfall in New-Bussa will be State1, 27\% will be state 2 and $3 \%$ of the annual rainfall will be State 3 . These equilibrium probabilities are independent of the initial state. That is be it in State 1, State2 and State 3 . The model could therefore be used to make a forecast of the annual rainfall pattern. This could providesome information for the Crop andFish farmers, artisanalFishermen, the Hydroelectric Power generating station and the government thatcould be used to plan strategies to boost their production in area.

\section{References}

[1]. Allen, D.M. and Haan, C.T., (1975). Stochastic simulation of daily rainfall. Res. Rep. No. 82 Water Resour. Inst., Univ.,Lexington, Kentucky, USA

[2]. Akintunde A.A, Asiribo O.E. Adebanji A.O. Adelakun A.A Agwuegbo S.O.N. (2008) Stochastic modelling of daily precipitation in Abeokuta, proceedings of the third Conference on science and National Development pp108-118 www.unaab.edu.ng/journal/index.php/COLNAS/article/.../150/153. Accessed 15/10/2012.

[3]. Jimoh, O. D. and Webster, P. (1996). Optimum order of Markov chain for daily rainfall in Nigeria. Journal ofHydrology 185 : $45-69$.

[4]. RatnasinghamSrikanthan and Tom McMahon(2000):Stochastic Generation ofClimate Data, A Review:Technical Report 00/16, Cooperative Research Centre for Catchment Hydrology, Australia

[5]. Gabriel, K. R. and Neumann, J. (1962) A Markov chain model for daily rainfall occurrences at Tel Aviv. Quart. J. Roy. Met. Soc. 88:90-95

[6]. Jimoh, O. D. and Webster, P. (1999). Stochastic modelling daily rainfall in Nigeria: intra- annual variation of model parameters. Journal of Hydrology 222:1- 17

[7]. Kottegoda, N. T., Natale, L. and Raiteri, E. (2004); Some considerations of periodicity and persistence in daily rainfalls, J. Hydrol. 296:23-37.

[8]. Howard R.A.(1971), Dynamic Probabilistic Systems, Vols.1and2. John Wiley, New York.

[9]. Tamil.S. and Samuel, S. (2011). Stochastic Modelling of Annual Rainfall at Tamil Nadu, Universal Journal of Environmental Research and Technology, Volume 1, Issue 4: 566-570

[10]. AbubakarUsman Yusuf, LawalAdamu, MuhammedAbdullahi(2014). Markov Chain Model and Its Application to Annual Rainfall Distribution for Crop Production. American Journal of Theoretical and Applied Statistics. Vol. 3, No. 2, pp. 39-43.

[11]. Abubakar U.Y., Lawal A., Muhammed A. (2013). The Use of Markov Model in Continuous Time for the Prediction ofRainfall for Crop Production, International Organization of Scientific Research, (IOSR) Vol.7, Issue1, pp $38-45$.

[12]. Cox D.R., and Miller H.D. (1984). The Theory of Stochastic Processes. Chapman and Hall London.

[13]. The archive of National Institute for Freshwater Fisheries Research(NIFFR), New-Bussa(2014) 